criteria and terminologies in clinical communication improved trainees' use of ICD-10 diagnoses. This type of audit, to the best of our knowledge, has not been previously performed.

Despite the small number of cases in this study, the issue of trainees' familiarity with standard diagnostic classification systems, especially ICD, is important because it is expected that all trainees, irrespective of location, are taught how to assess patients and communicate with colleagues. Familiarity with ICD criteria is also vital in the preparation for the membership examinations of the Royal College of Psychiatrists, in which it is often tested. Our study findings and recommendations have broad relevance in this regard.

\section{Limitations}

It is not always possible at the point of admission to know the exact ICD-10 code, as the diagnosis may still be unclear, but a good working diagnosis at this stage will inform appropriate intervention. The small sample size of this study is also an issue. It is uncertain how far the results of this local audit may be generalised. This audit was based on ICD-10 and this is expected to be soon superseded by ICD-11 and DSM-V.

\section{Conclusion}

Use of ICD-10 diagnoses is an important part of psychiatric training. It enhances good clinical practice and is often tested in College examinations. Emphasis on ICD-10 diagnostic criteria and terminologies during ward rounds, and in every form of clinical communication, should be encouraged at every stage of training. Psychiatric trainees should be taught their use in order to bring their clinical practice up to the College standard.

\section{References}

Crossan, I., Curtis, D. \& Ong, Y. L. (2004) Audit of psychiatric discharge summaries: completing the cycle. Psychiatric Bulletin, 28, 329-331.

Johnston, G., Cromble, I. K., Alder, E. M., et al (2000) Reviewing audit: barriers and facilitating factors for effective clinical audit. Quality in Health Care, 9, 23-36.

Royal College of Psychiatrists (2003) Guidance Notes for Applications under Article 14(4) and 14(5)(a) of the General and Specialist Medical Practice (Education, Training and Qualifications) Order. See http://www. rcpsych.ac.uk/pdf/GuidlinesPMETBApp.pdf (accessed September 2011).

World Health Organization (1992) The ICD-10 Classification of Mental and Behavioural Disorders (10th revision) (ICD-10). WHO.

\title{
Being monolingual, bilingual or multilingual: pros and cons in patients with dementia
}

\section{Farooq Khan MBBS MD MRCPsych}

Specialist Registrar in Old Age Psychiatry, Black Country NHS Partnership Trust, and Honorary Lecturer, Centre for Ageing and Mental Health, Staffordshire University, UK, email f.khan@staffs.ac.uk

\begin{abstract}
his article looks at the advantages and disadvantages of being monolingual or multilingual, with particular reference to dementia patients who belong to ethnic minorities. There has been some progress in understanding the field of cultural diversity and the variations between different ethnic groups in relation to their specific difficulties when suffering from dementia (Hendrie et al, 2001). However, research has largely been targeted towards cultural variations and dementia, while the language aspects have not been properly researched.

The National Dementia Strategy was launched in the UK in 2009. It highlights the needs of dementia patients who belong to ethnic minorities and tries to predict what problems may arise if services are not appropriately geared to managing this particular group.

There is an increasing need to understand the linguistic changes faced by multilingual patients from ethnic minorities who suffer from dementia. A more comprehensive
\end{abstract}

understanding of this group of patients could be achieved if professionals were aware of some of the implications of multilingualism for their patients.

Language has been described as comprising symbols that convey meaning and also the rules for combining those symbols. By definition 'monolingual' means the ability to speak only one language, 'bilingual' two languages and 'multilingual' several languages.

D'Acierno (1990) describes the acquisition of a first language as an intrinsic component of a child's overall social and cognitive development, whereas the learning of a second language need not be so. D'Acierno also noted three types of bilingualism: compound bilingualism, coordinate bilingualism and sub-coordinate bilingualism. Individuals who learn two languages in the same environment so that they acquire one notion with two verbal expressions are compound bilinguals. A coordinate bilingual person acquires the two languages in different contexts, say in home and 
in school, so that the words of two languages belong to separate and independent systems. In sub-coordinate bilingualism, one language dominates.

\section{Findings in aphasic multilinguals or polyglots}

In aphasic multilingual patients, recovery in one language is usually accompanied by recovery in another, but non-parallel recovery is also seen (Mendez et al, 1999). The language first recovered may be the one acquired earliest, the predominant one or the one spoken in the patient's environment.

In dementia, new information is retained the least well and older information is preserved for longer; this is similar to what is observed in multilingual patients who revert to their mother tongue (i.e. the earliest acquired language) (Mendez et al, 1999). This phenomenon was highlighted in a survey of bilingual aphasic patients who had suffered from asymmetrical language impairment, with preservation of their first acquired language (Paradis, 1997).

There are differences in the physiological brain function of early and late bilinguals, for example in the left inferior frontal gyrus, which modulates syntactic processing, word generation and sentence generation. Further differences have been observed in the grey-matter density of the posterior parietal cortex, as well as in right-hemisphere involvement (Wattendorf \& Festman, 2008).

Perani et al (1998) studied individuals who had learnt their second language either early or late, and who had varying degrees of proficiency in their second language, using a sample of individuals who spoke Italian and English or Spanish and Catalan. They found that the degree of proficiency was more important than age of acquisition of the second language as a determinant of cortical representation.

\section{Findings in relation to dementia in monolingual versus multilingual patients}

Language 'separation' as dementia progresses has been studied by Hyltenstam \& Obler (1989). Multilingual dementia patients regress to their original language as a result of an exacerbation of their cross-language difficulties, and this process advances with age. But bilinguals have also been observed not to deactivate either of their languages, which results in interference of their second language by their first (dominant) language (Hyltenstam \& Obler, 1989).

Mendez et al (1999) studied 51 patients of varying fluency in both English and another language who were having progressive memory or cognitive problems. In this study most patients communicated in their native language with family or friends and English was used only in a rudimentary form and only outside the home. Despite these patients' differences in educational level, the age at acquisition of English, the frequency of use and their baseline fluency in English, all their caregivers reported that these patients had a preference for their original, primary language. When talking in English, the caregivers reported that words from their mother tongue intruded into the patient's conversation.

\section{The advantages of being multilingual in relation to dementia}

Bialystok et al (2006) examined the role of a lifelong bilingual status in maintaining cognitive functioning and delaying the onset of symptoms of dementia in old age. A cohort of 228 patients (of whom $51 \%$ were bilingual) with varying degrees of cognitive impairment was followed up in a memory clinic. The bilinguals presented with symptoms of dementia 4 years later than monolinguals. All the other components of their cognitive assessments were similar.

The mother tongue or primary language appears to be maintained longer because it is stored using implicit strategies, whereas the second language is stored using explicit strategies (Fabbro, 2002). Language is used not only in social relationships but also to control cognitive processes. These findings suggest that there are significant differences between bilinguals and monolinguals in relation to age-associated cognitive decline during both normal and abnormal ageing, as indicated by Ardila \& Ramos (2010). Their research review suggests that normal ageing is associated with increased interference between two languages and that reverting to the primary language can be considered a predictor of dementia; it has also been found that bilinguals are usually faster in performing attention tasks and more efficient at carrying out tests that require executive control than monolinguals (Ardila \& Ramos, 2010).

A study was conducted by Howard (2010) in Montreal (Canada) on patients suffering from Alzheimer's dementia who were multilingual immigrants in Canada or bilingual non-immigrants who had grown up speaking both Canadian languages - French and English. The study reported a small but significant protective effect in relation to both the diagnosis and the age of symptom onset of Alzheimer's dementia in those who spoke more than two languages; they did not find a similar significant benefit in the bilinguals. In relation to the immigrant group they found that speaking two or more languages delayed the onset of dementia for 5 years on average, which was similar to the findings of Bialystok et al (2006).

To illustrate this phenomenon, we can look at the case of a 61-year-old bilingual Spaniard who suffered from Alzheimer's dementia and spoke both Italian and Spanish. Neuropsychological assessments were performed and an individualised integral cognitive stimulation programme was given to him that lasted 3 years. His progress was followed up by a series of cognitive tests in both languages. As the illness progressed the patient had increasing difficulty in separating the two languages and had frequent intrusions of either language. In this patient the first language, which was Italian, remained intact for a longer period, as suggested in the studies referred to above. Italian intrusions of his mother tongue were found during his test sessions in Spanish (his second language) and vice versa. Gradually, this patient started to respond mainly in Italian, even though the tests and questions were given in Spanish (Diaz \& Peraita, 2008). In patients suffering from dementia, both comprehension and the ability to speak in the primary language are preserved longer than comprehension and the ability to speak in both the second and third language. 


\section{Conclusion}

There does seem to be sufficient evidence to conclude that as dementia advances with age, patients who speak two or more languages have a tendency to revert to their primary language. It does also appear that bilingual and multilingual immigrants from various geographical backgrounds appear to be protected from the onset of dementia for about 4 years. In terms of the National Dementia Strategy referred to above, these linguistic issues are important in the treatment of aphasic bilingual or multilingual patients. If we are to provide information and make people aware of the implications of their illness, further research is necessary which could lead to improved communication and care for these patients suffering from dementia who belong to ethnic minorities.

\section{References}

Ardila, A. \& Ramos, E. (2010) Bilingualism and aging. Perspectives on Communication Disorders and Sciences in Culturally and Linguistically Diverse Populations, 17, 74-81.

Bialystok, E., Craik, F. I. \& Freedman, M. (2006) Bilingualism as a protection against the onset of symptoms of dementia. Neuropsychologia, 42, 459-464.
D'Acierno, M. R. (1990) Three Types of Bilingualism. Educational Resources Information Centre (ERIC). At http://www.eric.ed.gov:80/PDFS/ ED321574.pdf (accessed 3 June 2011).

Diaz, C. \& Peraita, H. (2008) Neuropsychological evaluation and cognitive evolution of a bilingual Alzheimer patient. Revista de Psicopatología y Psicología Clínica, 13, 219-228.

Fabbro, F. (2002) The bilingual brain: cerebral representation of languages. Brain and Language, 79, 211-222.

Hendrie, H. C., Ogunniyi, A., Hall, K. S., et al (2001) Incidence of dementia and Alzheimer disease in 2 communities: Yoruba residing in Ibadan, Nigeria, and African Americans residing in Indianapolis, Indiana. JAMA, 285, 739-747.

Howard, C. (2010) Multilingualism (but not always bilingualism) delays the onset of Alzheimer disease: evidence from a bilingual community. Alzheimer Disease and Associated Disorders, 24, 118-125.

Hyltenstam, K. \& Obler, L. K. (1989) Bilingualism Across the Lifespan: Aspects of Acquisition, Maturity, and Loss. Cambridge University Press.

Mendez, M. F., Perryman, K. M., Pontoon, M. O., et al (1999) Bilingualism and dementia. (Letter.) Journal of Neuropsychiatry and Clinical Neurosciences, 11, 411-412.

Paradis, M. (1997) The Assessment of Bilingual Aphasia. Lawrence Erlbaum.

Perani, D., Paulesu, E., Galles, S. B., et al (1998) The bilingual brain proficiency and age of acquisition of second language. Brain, 121, 1841-1852.

Wattendorf, E. \& Festman, J. (2008) Images of the multilingual brain: the effect of age of second language acquisition. Annual Review of Applied Linguistics, 28, 3-24.

\section{Psychiatrists are stakeholders in improving access to controlled medicines}

\section{Willem Scholten PharmD MPA}

Team Leader, Access to Controlled Medicines, Department of Essential Medicines and Pharmaceutical Policies, World Health Organization, Geneva, Switzerland, email ScholtenW@who.int

M edicines made from substances that are controlled under the international drug control treaties ('controlled medicines') are out of reach for the majority of patients around the world. Seya et al (2011) demonstrated that 5.5 billion people ( $83 \%$ of the world's population) live in countries with little or no access to opioid analgesics, 250 million (4\%) have moderate access and only 460 million people (7\%) have adequate access. Insufficient data are available for 430 million (7\%). If the need for treatment of moderate to severe pain were to be satisfied adequately, the global consumption of strong opioid analgesics would go up from 231 tonnes of morphineequivalents to 1292 tonnes.

Controlled medicines belong to a number of therapeutic classes. The World Health Organization (WHO) has produced a Model List of Essential Medicines and a Model List of Essential Medicines for Children. Among the controlled medicines on these lists are: opioid analgesics; long-acting opioids for the treatment of opioid dependence; medicines for emergency obstetrics; benzodiazepines both for mental disorders and against epilepsy; and phenobarbital, also an anti-epileptic. Ketamine is listed as an 